\title{
Neonatal administration of citalopram delays somatic maturation in rats
}

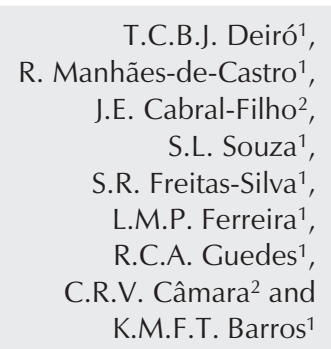

T.C.B.J. Deiró ${ }^{1}$, R. Manhães-de-Castro ${ }^{1}$,

J.E. Cabral-Filho ${ }^{2}$, S.L. Souza ${ }^{1}$, S.R. Freitas-Silva ${ }^{1}$, L.M.P. Ferreira ${ }^{1}$, R.C.A. Guedes ${ }^{1}$, C.R.V. Câmara ${ }^{2}$ and K.M.F.T. Barros ${ }^{1}$

\author{
'Departamento de Nutrição, Centro de Ciências da Saúde, \\ Universidade Federal de Pernambuco, Recife, PE, Brasil \\ ${ }^{2}$ Instituto Materno Infantil de Pernambuco, Recife, PE, Brasil
}

\author{
Correspondence \\ R. Manhães-de-Castro \\ Departamento de Nutrição \\ Centro de Ciências da Saúde, UFPE \\ Av. Morais Rego, 1235 \\ 50670-901 Recife, PE \\ Brasil \\ Fax: +55-81-3271-8473 \\ E-mail: rcastro@nutricao.ufpe.br
}

Research supported by CNPq and PROIN/CAPES.

Received October 31, 2003 Accepted June 28, 2004

Accepted

\begin{abstract}
We investigated the somatic maturation of neonate rats treated during the suckling period with citalopram, a selective serotonin reuptake inhibitor. Groups with 6 male neonates were randomly assigned to different treatments $24 \mathrm{~h}$ after birth. Each litter was suckled by one of the dams until the 21st postnatal day. Body weight, head axis and tail length were measured daily from the 1 st to the 21 st postnatal day. Time of ear unfolding, auditory conduit opening, incisor eruption, and eye opening was determined. Pups received $5 \mathrm{mg}$ (Cit5), $10 \mathrm{mg}$ (Cit10) or $20 \mathrm{mg} / \mathrm{kg}$ (Cit20) citalopram $s c$, or saline $(0.9 \% \mathrm{NaCl}, \mathrm{w} / \mathrm{v}$, sc). Compared to saline, body weight was lower $(24.04 \%, \mathrm{P}<0.01)$ for Cit10 from the 10th to the 21st day and for Cit20 from the 6th to the 21 st day $(38.19 \%, \mathrm{P}<0.01)$. Tail length was reduced in the Cit20 group $(15.48 \%, \mathrm{P}<0.001)$ from the 8 th to the 21 st day. A reduction in mediolateral head axis $(10.53 \%, \mathrm{P}<0.05)$ was observed from the 11 th to the 21st day in Cit10 and from the 6th to the 21st day in Cit20 $(13.16 \%, \mathrm{P}<0.001)$. A reduction in anteroposterior head axis was also observed in the Cit20 group $(5.28 \%, \mathrm{P}<0.05)$ from the 13 th to the $21 \mathrm{st}$ day. Conversely, this axis showed accelerated growth from the 12th to the 21 st day in the Cit5 group $(13.05 \%, \mathrm{P}<0.05)$. Auditory conduit opening was delayed in the Cit5 and Cit20 groups and incisor eruption was delayed in all citalopram groups. These findings show that citalopram injected during suckling to rats induces body alterations and suggest that the activity of the serotoninergic system participates in growth mechanisms.
\end{abstract}

\section{Introduction}

Selective serotonin reuptake inhibitors (SSRI) such as citalopram have been used to induce increased serotoninergic activity in the brain $(1,2)$. Experimental evidence indicates that serotonin can influence embryo-
Key words

- Serotonin

- Growth indicators

- Selective serotonin

reuptake inhibitor

- Citalopram

- Craniofacial

- Skull genesis and growth $(3,4)$ presumably by acting as a developmental signal (5) or as a neurotrophic factor as well (6). Furthermore, serotonin seems to play a role in regulating the development of the mammalian brain through its action on the production of self serotonin neurons $(4,7,8)$ and on target tis- 
sues innervated by serotoninergic neurons (9-11). Pharmacological or nutritional manipulations during pregnancy or the suckling period can induce drastic morphological and functional changes in the growth and development of the nervous system (12-16). Several studies have shown that treatment with SSRI reduces food intake and body weight in rats $(17,18)$. A hypophagic effect was observed following fluoxetine administration (19). As a consequence, the possibility exists that the use of serotoninergic agents in the early phase of life could influence other specific maturation processes in the body. Therefore, it is desirable to investigate the possible effects of manipulation of the serotoninergic system early in life.

The objective of the present study was to test the hypothesis that the administration of citalopram - a highly SSRI (20) - to rats during the suckling period induces changes in somatic development and in body growth.

\section{Material and Methods}

\section{Animals}

Litters obtained from dams mated to male Wistar rats from the colony of the Nutrition Department, Federal University of Pernambuco, Recife, PE, Brazil, were used in the present study. During gestation and until the end of the experiment, the animals were housed in polyethylene cages. Male pups from different mothers $(\mathrm{N}=18)$ were randomly divided into groups of 6 neonates 24 $\mathrm{h}$ after birth. Each pup was marked with methyl violet solution on the skin for identification during the experiment. Each litter was suckled by one of the dams until the 21st postnatal day (birth day was considered to be zero day). The animals were maintained at a room temperature of $23 \pm 1^{\circ} \mathrm{C}$, on a $12 / 12$-h light-dark cycle (lights from 6:00 am to 6:00 $\mathrm{pm}$ ) with free access to ration (Labina-Purina, São Lourenço da Mata, PE, Brazil) and water.

\section{Citalopram}

The experiment was performed blind to prevent identification of the experimental groups. The animals of the different groups were evaluated simultaneously. For the experimental treatment, four groups $(\mathrm{N}=27$ each) of suckling rats were distributed as follows: three groups received citalopram: group Cit5 (5 mg/kg, sc), group Cit10 (10 $\mathrm{mg} / \mathrm{kg}, s c)$, and group Cit20 (20 mg/kg, sc), and a control group received an equivalent volume of saline $(0.9 \% \mathrm{NaCl}, \mathrm{w} / \mathrm{v}) s c$. During the experiment, one neonate rat in the Cit20 group and one in the Cit5 group died. Therefore, 106 rats were evaluated. The time of physical feature maturation and somatic growth was recorded. Citalopram (H. Lundbeck A/S, Copenhagen-Valby, Denmark), was dissolved in saline and $1 \mathrm{ml} / 100 \mathrm{~g}$ body weight was injected $s c$. The treatment was applied daily from the 1 st to the 21 st postnatal day (suckling period) at 0:30-1:30 pm.

\section{Physical feature maturation}

The following physical features were observed: unfolding of the external pinnae of both ears to the fully erect position; internal auditory conduit opening of both ears; incisor eruption, i.e., the first visible and palpable crest of lower incisors, and eye opening, i.e., when any visible break in the covering membrane of both eyes was detected. The features were evaluated daily between 10:00 and 12:00 am by the method of Smart and Dobbing (21) during the suckling period until maturation of the variable. The maturation age of a particular feature was defined as the day it was first observed.

\section{Somatic growth}

Somatic growth was assessed in terms of body weight, tail length, and mediolateral and anteroposterior head axis measurements made from the 1 st to 21 st postnatal day 
between 1:00 and 2:00 pm as follows: body weight was measured with a FANEM scale (São Paulo, SP, Brazil) with $100 \mathrm{mg}$ precision. Tail length (distance from tail tip to tail base), length of the mediolateral skull axis (distance between the ear holes), and length of the anteroposterior axis of the head (distance between snout and head-neck articulation) were measured with a Starret caliper with $0.05 \mathrm{~mm}$ precision.

\section{Statistical analysis}

Statistical analysis was performed after preliminary testing to identify normality of distribution and homogeneity of variance among the groups. Two-way ANOVA for repeated measures (from the 1 st to the $21 \mathrm{st}$ day for body weight, head axis and tail length) followed by the post hoc Tukey test were used to compare growth indicators between each citalopram group and the saline control. Kruskal-Wallis analysis of variance followed by the Dunn test was used to compare physical features between each citalopram group and the saline control. The level of significance was set at $\mathrm{P}<0.05$.

The experimental protocol of the study was approved by the Ethics Committee for Animal Experimentation of the Federal University of Pernambuco, and was consistent with the National Institute of Health Guide for Care and Uses of Laboratory Animals (Publication No. 85-23, revised, 1985).

\section{Results}

ANOVA identified main effects of time and treatment in addition to interaction between these factors regarding somatic growth. For body weight, statistical analysis showed an effect of citalopram $\left(\mathrm{F}_{3,102}=52.9, \mathrm{P}<\right.$ $0.001)$, and day of life $\left(\mathrm{F}_{20,2040}=2340.6, \mathrm{P}<\right.$ $0.001)$ as well as a citalopram versus day of life interaction $\left(\mathrm{F}_{60,2040}=69.5, \mathrm{P}<0.001\right)$. Body weight gain (Figure 1A) was reduced from the 10th to the 21st day $(24.04 \%, \mathrm{P}<$
0.01) in Cit10 and from the 6th to the 21st day $(38.19 \%, \mathrm{P}<0.01)$ in Cit20 when compared to saline. This lower weight gain was more marked in the Cit20 than in the Cit10
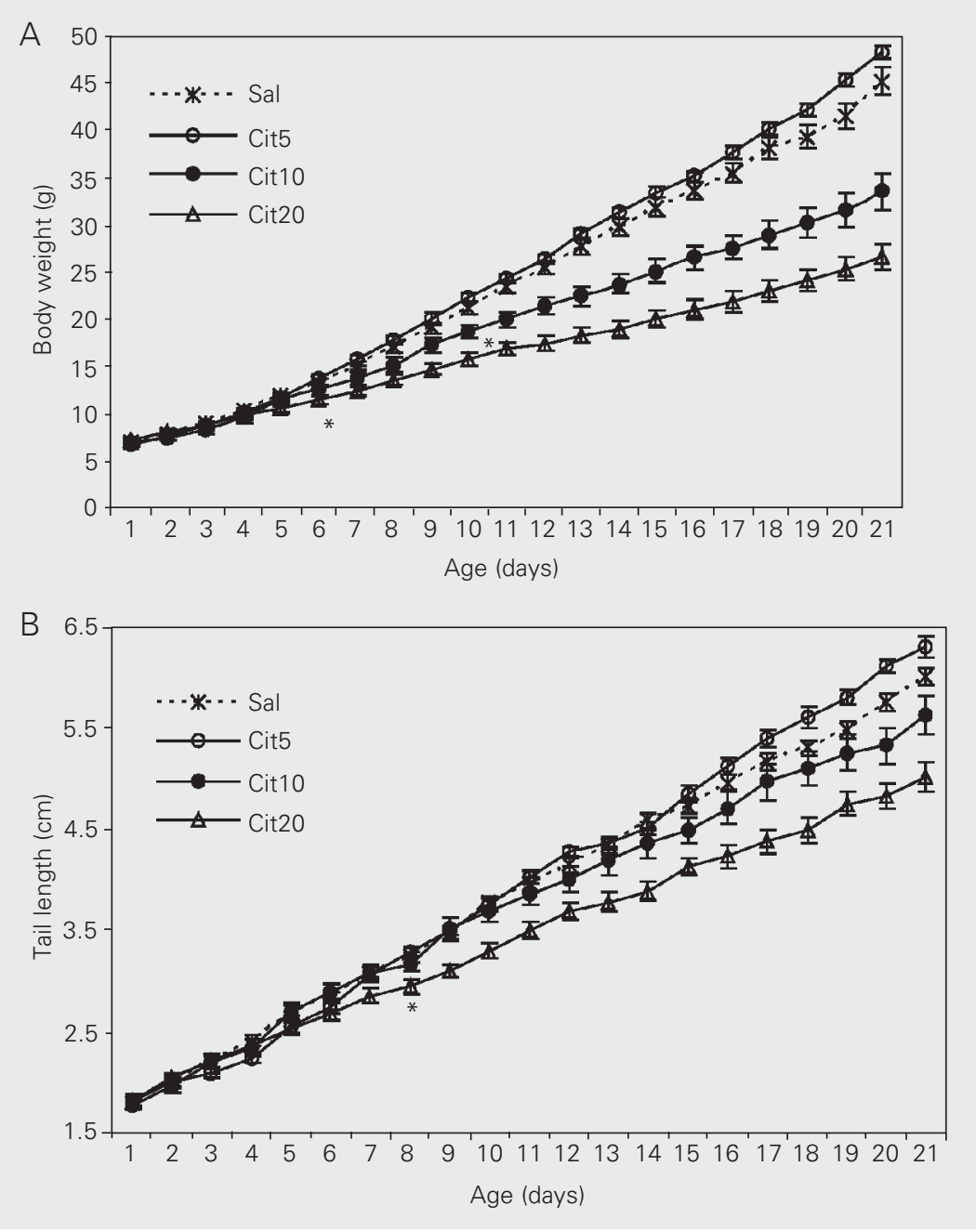

Figure 1. Effect of citalopram on suckling rat weight and tail length. $A$, Body weight from the $1 \mathrm{st}$ to the $21 \mathrm{st}$ day of life of suckling rats treated with solutions $(1 \mathrm{ml} / 100 \mathrm{~g}$ body weight, sc) of citalopram: $5 \mathrm{mg}$ (Cit5, N = 26), $10 \mathrm{mg}$ (Cit10, N = 27) and $20 \mathrm{mg} / \mathrm{kg}$ (Cit20, N $=26$ ) or saline (Sal, $N=27$ ). Comparisons were made by two-way ANOVA for repeated measures: citalopram $\left(F_{3,102}=52.9, P<0.001\right)$, day of life $\left(F_{20,2040}=2340.6, P<0.001\right)$, and citalopram versus day of life interaction $\left(F_{60,2040}=69.5, P<0.001\right)$ followed by post hoc multiple comparisons (Tukey test) between each citalopram dose and saline: ${ }^{*} \mathrm{P}<$ 0.001 . Each point represents the mean values according to the dose. The asterisks indicate the beginning of significant differences $(P<0.01)$ that persisted through the end of the experiment. $B$, Tail length. Comparisons were made by two-way ANOVA for repeated measures: citalopram $\left(F_{3,102}=13.7, P<0.001\right)$, day of life $\left(F_{20,2040}=3198.0, P<0.001\right)$, and citalopram versus day of life interaction $\left(F_{60,2040}=18.7, P<0.001\right)$ followed by post hoc multiple comparisons (Tukey test) between each citalopram dose and saline: each point represents the mean values according to the dose. The asterisk indicates the beginning of significant differences $(P<0.01)$ which persisted to the end of the experiment according to the dose. 
group. The Cit5 group did not differ from saline (Figure 1A).

For tail length (Figure 1B), statistical analysis showed a main effect of citalopram $\left(\mathrm{F}_{3,102}=13.7, \mathrm{P}<0.001\right)$ and day of life $\left(\mathrm{F}_{20,2040}=3198.0, \mathrm{P}<0.001\right)$ in addition to
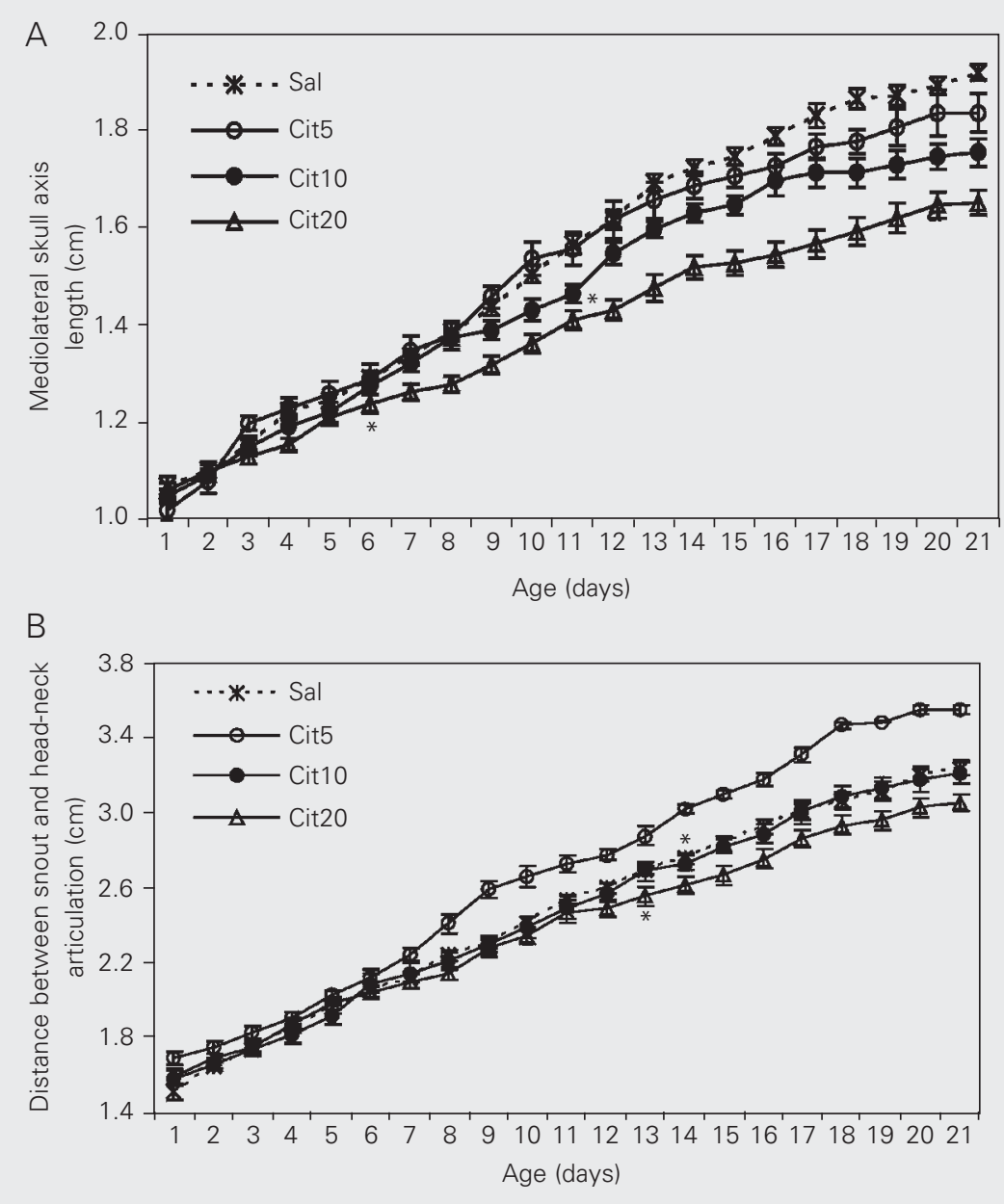

Figure 2. Effect of citalopram on suckling rat mediolateral skull axis length and distance between snout and head-neck articulation. A, Mediolateral skull axis from the 1st to $21 \mathrm{st}$ day of life of suckling rats treated with solutions $(1 \mathrm{ml} / 100 \mathrm{~g}$ body weight, $s c)$ of citalopram: $5 \mathrm{mg}(\mathrm{Cit5}, \mathrm{N}=26), 10 \mathrm{mg}$ (Cit10, $\mathrm{N}=27$ ) and $20 \mathrm{mg} / \mathrm{kg}$ (Cit20, $\mathrm{N}=26$ ) or saline (Sal, $\mathrm{N}=$ 27). Comparisons were made by two-way ANOVA for repeated measures for citalopram $\left(F_{3,102}=23.8, P<0.001\right)$ and day of life $\left(F_{20,2040}=1622.1, P<0.001\right)$ and citalopram versus day of life interaction $\left(F_{60,2040}=15.3, P<0.001\right)$ followed by post hoc multiple comparisons (Tukey test) between each citalopram dose and saline. The asterisks indicate the beginning of significant difference in the Cit10 group $(P<0.05)$ and Cit20 group $(P<$ 0.001 ) that persisted to the end of the experiment. $B$, Distance between snout and headneck articulation. Comparisons were made by two-way ANOVA for repeated measures: citalopram $\left(F_{3,102}=15.1, P<0.001\right)$, day of life $\left(F_{20,2040}=2770.6, P<0.001\right)$, and citalopram versus day of life interaction $\left(F_{60,2040}=14.7, P<0.001\right)$ followed by post hoc multiple comparisons (Tukey test) between each citalopram dose and saline. The asterisks indicate the beginning of significant differences for Cit20 $(P<0.01)$ and Cit5 $(P<0.05)$ that persisted to the end of the experiment. an interaction between citalopram and day of life $\left(\mathrm{F}_{60,2040}=18.7, \mathrm{P}<0.001\right)$. A reduced growth of tail length was observed in the Cit20 group from the 8th to the 21st day $(15.48 \%, \mathrm{P}<0.01)$; however, the Cit10 and Cit5 groups did not differ from the saline control.

ANOVA showed an effect of citalopram $\left(\mathrm{F}_{3,102}=23.8, \mathrm{P}<0.001\right)$ and day of life $\left(\mathrm{F}_{20,2040}=1622.1, \mathrm{P}<0.001\right)$, as well as an interaction between citalopram and day of life $\left(\mathrm{F}_{60,2040}=15.3, \mathrm{P}<0.001\right)$ on the mediolateral head axis. A reduction in mediolateral head axis growth was observed from the 11th to the 21st day in the Cit10 group $(10.53 \%, \mathrm{P}<0.05)$, and from the 6 th to the 21st day in the Cit20 group (13.16\%, P $<0.001)$ compared to the saline control. Moreover, the reduced growth of this axis was more marked for the $20 \mathrm{mg}$ dose than for the $10 \mathrm{mg}$ dose (Figure 2A).

There was also a significant change in growth of the anteroposterior head axis length. There were effects of citalopram $\left(F_{3,102}=15.1, P<0.001\right)$, day of life $\left(F_{20,2040}\right.$ $=2770.6, \mathrm{P}<0.001)$ and interaction between citalopram and day of life $\left(\mathrm{F}_{60,2040}=\right.$ $14.7, \mathrm{P}<0.001)$. In the Cit20 group a reduction of this axis occurred from the 13th to the 21 st day $(5.28 \%, \mathrm{P}<0.01)$, whereas the growth was accelerated from the 12th to the 21 st day in the Cit5 group $(13.05 \%, \mathrm{P}<$ $0.05)$. There was no difference for the Cit10 group (Figure 2B).

\section{Physical features}

For physical feature maturation (Table 1), Kruskal-Wallis analysis indicated significant changes in auditory conduit opening $(\mathrm{H}=10.59, \mathrm{P}<0.05)$ and incisor eruption $(\mathrm{H}$ $=19.33, \mathrm{P}<0.01)$ in the citalopram groups. Multiple comparisons of these features among treatment groups (Dunn test) showed that auditory conduit opening was delayed in the Cit5 $(\mathrm{P}<0.05)$ and Cit20 groups $(\mathrm{P}<$ $0.05)$. Incisor eruption was delayed in the 
Cit5 (P < 0.05), Cit10 ( $<<0.01)$ and Cit20 (P $<0.05)$ groups. It is noteworthy that a wide variation (11-18 days for auditory conduit opening and 10-17 days for incisor eruption) was observed in the Cit20 group but not in groups receiving the lowest citalopram doses or saline. For eye opening and ear unfolding there was no significant difference.

\section{Discussion}

The present results show that chronic administration of citalopram during the critical neonatal period of rat brain development induces changes in growth. In general the drug impaired somatic growth and physical body maturation. As observed for body weight, increasing doses of citalopram resulted in equivalent growth alteration of tail and head. Regarding craniofacial development, the heads of the animals became longer with the lowest citalopram dose, narrower with the middle dose and both shorter and narrower with the highest dose. Therefore, the head suffered a shape distortion during development that was dependent on the dose of citalopram. The sensitivity of vertebrate head growth to epigenetic manipulations has been well demonstrated $(22,23)$. Changes in the craniofacial skeleton of developing rats submitted to a low protein diet were shown by Miller and German (24). Some of these changes consisted of shortening of skull dimensions, a result similar to that experienced by the animals receiving $20 \mathrm{mg}$ citalopram in the present study. It is noteworthy that early protein malnutrition such as studied by Miller and German (24) is known to increase brain serotonin (5-HT) levels (13). Therefore, it is appropriate to consider the delayed development of the structures inside the skull (auditory conduit) and face (lower incisors) observed in the present study, because the delays might be associated with reduced head growth. Furthermore, the interaction between citalopram and time indicates that the highest citalopram dose caused not only a reduction of body weight gain and of tail growth, but also that these reductions in rats receiving $20 \mathrm{mg}$ began earlier than in animals receiving the two lowest doses. These changes are important because they indicate the existence of growth mechanisms in body tissues which are sensitive to the dose of citalopram. Since this drug increases serotonin release (20) we suggest that serotoninergic mechanisms may be responsible for the effects of citalopram.

In addition, there is evidence that SSRI and some serotoninergic agonists also increase 5-HT release not only in neuronal tissues $(10,11,25)$ but also in non-neuronal tissues $(26,27)$. Interestingly, serotonin has a trophic action on the differentiation of sev-

\begin{tabular}{|c|c|c|c|c|}
\hline \multirow[t]{2}{*}{ Physical features } & \multirow[t]{2}{*}{ Saline $(N=27)$} & \multicolumn{3}{|c|}{ Citalopram (mg/kg) } \\
\hline & & $5(N=26)$ & $10(N=27)$ & $20(N=26)$ \\
\hline Ear unfolding & $3.0(1-4)$ & $3.0(2-6)$ & $3.0(2-4)$ & $3.0(2-5)$ \\
\hline Auditory conduit opening & $12.0(11-14)$ & $13.0(12-14)^{*}$ & $12.5(12-14)$ & $13.0(11-18)^{*}$ \\
\hline Eruption of the lower incisors & $12.0(9-13)$ & $13.0(12-14)^{*}$ & $12.0(11-15)^{*}$ & $12.0(10-17)^{*}$ \\
\hline Eyes opening & $14.0(12-15)$ & $14.0(12-16)$ & $14.0(12-14)$ & $14.0(12-17)$ \\
\hline
\end{tabular}

Kruskal-Wallis analysis of variance followed by the Dunn test were used to compare physical features between each citalopram dose and the saline control group. A significant change in auditory conduit opening $(H=10.59, P<0.05)$ and incisor eruption $(H=19.33, P<0.01)$ was observed in the citalopram groups. Data are reported as median and range (in parentheses).

${ }^{*} \mathrm{P}<0.05$ compared to control. 
eral tissues during the prenatal and postnatal periods $(27,28)$ by acting as a neurotrophic factor (6). Some studies on mouse embryo cultures treated with serotonin suggest an improved development of serotoninergic cells in the nervous tissue and of cells of the nasal prominence, epithelium covering the eye, optic vesicle, and oral cavity (10,29-33). These findings indicate that serotonin plays a role in the control of the epithelial-mesenchymal interactions during craniofacial morphogenesis (26). Serotoninergic treatment also caused malformation of both nerve and bone structures of mouse embryos (10). Several of these events begin in the second week of life and the first serotoninergic neurons appear as early as on the 12th to the 14th day of gestation (29). Therefore, during suckling the tissue may be able to respond to the challenge with citalopram. Moreover, a trophic role of 5-HT in the formation of craniofacial structures, including the maturation of the tooth germ, has been reported (28).

Our findings support the data in the literature because the delayed tooth eruption observed in the citalopram groups. However, the participation of citalopram in this maturation process appears to be complex since the highest dose induces a wider variation of the physical feature than the lowest doses. On the other hand, the possibility exists that the effects observed in this experiment may be induced by the action of 5-HT on anorectic mechanisms and not by a direct action of 5-HT on tissues. In fact, it has been well documented that hypophagia induced by citalopram reduces body weight in adult rats $(17,34)$ and body weight gain in young rats (16). Therefore, in the present experiment we could not rule out that the hypophagia induced by citalopram and the resulting malnutrition were capable of causing growth disorders in animals that received citalopram.

We conclude that citalopram administered during the period of rapid brain development causes important morphological body alterations. These data support the view that growth mechanisms are highly susceptible to the manipulation of the serotoninergic system during this period.

\section{References}

1. Toornvliet AC (1996). Serotoninergic drug-induced weight loss in carbohydrate craving obese patients. International Journal of Obesity and Related Metabolic Disorders, 20: 917-920.

2. Baumman P (1996). Pharmacology and pharmacokinetics of citalopram and other SSRIs. International Clinical Psychopharmacology, 11 (Suppl I): |-5-I-11.

3. Palén K, Thörneby L \& Emanuelsson H (1979). Effects of serotonin antagonists on chick embryogenesis. Wilhelm Roux's Archives of Developmental Biology, 187: 89-103.

4. Whitaker-Azmitia PM (1991). Role of serotonin and other neurotransmitter receptors in brain development: basis for developmental pharmacology. Pharmacological Reviews, 43: 553-561.

5. Liu J \& Lauder JM (1992). Serotonin promotes region-specific glial influences on cultures of serotonin and dopamine neurons. Glia, 5: 306-317.

6. Yan W, Wilson CC \& Haring JH (1997). 5-HT 1A receptors mediate the neurotrophic effect of serotonin on developing dentate granule cells. Developmental Brain Research, 98: 185-190.

7. Whitaker-Azmitia PM \& Azmitia EC (1986). Autoregulation of fetal serotonergic neuronal development: role of high affinity serotonin receptors. Neuroscience Letters, 67: 307-312.
8. Shemer AV, Azmitia EC \& Whitaker-Azmitia PM (1991). Dose-related effects of prenatal 5-methoxytryptamine (5-MT) on development of serotonin terminal density and behavior. Brain Research. Developmental Brain Research, 59: 59-63.

9. Lauder JM \& Krebs H (1976). Effects of p-chlorophenylalanine on time of neuronal origin during embryogenesis in the rat. Brain Research, 107: 638-644.

10. Lauder JM, Tamir H \& Sadler TW (1988). Sites of serotonin uptake and binding protein immunoreactivity in the midgestation mouse embryo. Development, 102: 709-720.

11. Lauder JM (1990). Ontogeny of serotonergic system in the rat: serotonin as a developmental signal. Annals of the New York Academy of Sciences, 600: 297-314.

12. Morgane PJ, Miller M, Kemper T, Stern W, Forbes W, Hall R, Bronzino J, Kissane J, Hawrylewicz E \& Resnick O (1978). The effects of protein malnutrition on the developing nervous system in the rat. Neuroscience and Biobehavioral Reviews, 2: 137-230.

13. Morgane PJ, Austin-Lafrance RJ, Bronzino J, Tonkiss J, Diaz-Cintra S, Cintra L, Kemper T \& Galler JR (1993). Prenatal malnutrition and development of the brain. Neuroscience and Biobehavioral Reviews, 17: 91-128. 
14. Noback CR \& Eisenman LM (1981). Some effects of protein-calorie undernutrition on the developing central nervous system of the rat. Anatomical Record, 201: 67-73.

15. Manhães-de-Castro R, Cabral-Filho JE, Costa JA, Costa FBR, Gallindo MAC \& Hecksher CA (1993). Neonatal treatment with naloxone causes permanent hyperalgesia in rats. Brazilian Journal of Medical and Biological Research, 26: 747-751.

16. Manhães-de-Castro R, Barreto Medeiros JM, Mendes da Silva C, Ferreira LMP, Guedes RCA, Cabral-Filho JE \& Costa JA (2001). Reduction of intraspecific aggression in adult rats by neonatal treatment with a selective serotonin reuptake inhibitor. Brazilian Journal of Medical and Biological Research, 34: 121-124.

17. Halford JCG \& Blundell JE (1996). Metergoline antagonizes fluoxetine-induced suppression of food intake but not changes in the behavioral satiety sequence. Pharmacology, Biochemistry, and Behavior, 54: 745-751.

18. McCann UD, Yuan J, Hatzidimitriou G \& Ricaurte GA (1997). Selective serotonin reuptake inhibitors dissociate fenfluramine's anorectic and neurotoxic effects: importance of dose, species and drugs. Journal of Pharmacology and Experimental Therapeutics, 281: 14871498.

19. Lightowler S, Wood M, Brown T, Glen A, Blackburn T, Tulloch I \& Kennett $G$ (1996). An investigation of the mechanism responsible for fluoxetine-induced hypophagia in rats. European Journal of Pharmacology, 296: 137-143.

20. Hyttel J (1994). Pharmacological characterization of selective serotonin reuptake inhibitors (SSRIs). International Journal of Psychopharmacology, 9 (Suppl): 19-26.

21. Smart JL \& Dobbing J (1971). Vulnerability of developing brain. VI. Relative effects of foetal and early postnatal undernutrition on reflex ontogeny and development of behaviour in the rat. Brain Research, 33: 303-314.

22. Herring SW (1993). Formation of the vertebrate face: epigenetic and functional influences. American Zoologist, 33: 472-483.

23. Dressino V \& Pucciarelli HM (1997). Cranial growth in Saimiri sciureus Cebidae and its alteration by nutritional factors: a longitudi- nal study. American Journal of Physical Anthropology, 102: 545554.

24. Miller JP \& German RZ (1999). Protein malnutrition affects the growth trajectories of the craniofacial skeleton in rats. Journal of Nutrition, 129: 2061-2069.

25. Buznikov GA (1990). Neurotransmiters in Embryogenesis. Harwood Academic Press, Chur, Switzerland.

26. Shuey DL, Sadler TW \& Lauder JM (1993). Serotonin as a regulator of craniofacial morphogenesis: site specific malformations following exposure to serotonin uptake inhibitors. Teratology, 46: 367378.

27. Lauder JM (1993). Neurotransmitters as growth regulatory signals: role of receptors and second messengers. Trends in Neurosciences, 16: 233-240.

28. Moiseiwitsch JRD \& Lauder JM (1996). Stimulation of murine tooth development in organotypic culture by the neurotransmitter serotonin. Arcchives of Oral Biology, 41: 161-165.

29. Lidov HGW \& Molliver ME (1982). An immunohistochemical study of serotonin neuron development in the rat: ascending pathways and terminal fields. Brain Research Bulletin, 8: 389-416.

30. Wallace JA \& Lauder JM (1983). Development of the serotonergic system in the rat embryo immunocytochemical study. Brain Research Bulletin, 10: 459-479.

31. Hall BK (1980). Viability and proliferation of epithelia and the initiation of osteogenesis in the mandibular ectomesenchyme in the embryonic chick. Journal of Embryology and Experimental Morphology, 56: 71-89.

32. Hall BK (1981). The induction of neural crest derived cartilage and bone by embryonic epithelia. An analysis of the mode of action of an epithelial-mesenchymal interaction. Journal of Embryology and Experimental Morphology, 64: 301-310.

33. Thorogood P (1981). Neural crest cells and skeletogenesis in vertebrate embryos. Histochemical Journal, 13: 631-642.

34. Halford JCG \& Blundell JE (2000). Pharmacology of appetite suppression. Progress in Drug Research, 5426-5458. 